\title{
オージェ電子分光分析装置内に構築した計測システムによる 固体間凝着力の支配機構の検討*
}

\author{
水野 亮二**，高橋 邦夫***，恩澤 忠男*** \\ Mechanism of adhesion force between solids by measurement system constructed \\ in Auger electron spectroscope*
}

by Ryoji Mizuno**, Kunio Takahashi*** and Tadao Onzawa***

\begin{abstract}
The force curves were measured in the ultra high vacuum (UHV) chamber of an Auger electron spectroscopy (AES) which is generally used for surface analysis. Contacts were made between a gold sphere of about $200 \mu \mathrm{m}$ radius and a silicon wafer. The specimens were sputtered by argon ion to clean their surfaces before the contact. No adsobates were observed in Auger spectra obtained from the sputtered surfaces.

Contact theory for adhesion between an elastic sphere and a rigid plane is described. This theory is based on Johnson, Kendall and Roberts (JKR) theory and Takahashi theory. The total energy in this system is a sum of the elastic energies in the sphere and the stiffness for the measurement system, the change of the surface energy within the contact region and surface-surface interaction outside of the contact region. The force curves are determined by the stiffness and the characteristic distance parameter of Lennard-Jones potential.

Experimental force curves were compared with the theoretical curves. Experimental force curves were influenced by vibration of experimental apparatus. It was suggested that surface-surface interaction was negligible under the order of radius of a gold sphere used to measure. Surface-surface interaction does not become negligible as radius of sphere becomes small. The developed measurement system reveabled informations of interatomic interaction and surface roughness.
\end{abstract}

Key Words: Adhesion force, Force curve, Contact theory, Lennard-Jones potential, Surface-surface interaction

\section{1. 緒}

言

固体間凝着力は接合・潤滑プロセスにおいて重要な因子 の一つである。固体間凝着力を物理的に理解し，プロセス に役立てるためには，実験的に計測した固体間凝着力を理 論に基づいて比較検討し，支配機構（メカニズム）を明ら かにする必要がある。我々は表面形状および表面状態を的 確に把握した上で様々な材料間で固体間凝着力を計測する ために，超高真空の表面分析装置内で固体間凝着力を計測 するシステムを試作している1,2).

固体間凝着力に関する理論としては JKR 理論3)，DMT 理論 ${ }^{4}$, MYD 理論5) がある.JKR 理論は接触部の表面エネ ルギーと界面エネルギーの差と弾性ひずみエネルギーのエ ネルギー平衡より接触している二固体を引き離すのに必要 な力を求めている．DMT 理論は接触部とその外側の表面 間相互作用を考慮して凝着力を求めているが，接触におけ る形と接触部の応力分布は Heltz の解に従うとしている. MYD 理論は JKR 理論とDMT 理論をまとめた理論であ り, 接触部の応力分布は Heltz の解と Boussinesq の解の 重权合わとしている。著者らは更に JKR 理論と MYD 理 論を基にして計測系の剛性を考慮に入れた変位一力曲線を 得ている ${ }^{6)}$.また, Burnham ら わ の AFM の実験によると表 面間の相互作用が無視できないことが示唆されている。本 研究の計測においても接触部以外の表面間の相互作用が疑 着力に影響を及涩寸可能性がある，高橋ら ${ }^{8)}$ は著者らの理 論に更に表面間の相互作用を考慮して変位一力曲線を得て いる. 本研究では, 高橋らの理論による変位一力曲線と本研

*原稿受付 平成 7 年11月28日 平成 7 年度秋季全国大会で発表

**学生員東京工業大学 Student Member, Tokyo Institute of Technology

***正 員 東京工業大学 Member, Tokyo Institute of Technology
究で計測した変位一力曲線とを比較検討する。そして, 本研 究で用いた計測システムにより固体間凝着現象の支配機構 について検剷を行う。

\section{2. 計測系の剛性と表面間相互作用 ${ }^{*}$ を 考慮した弾性接触理論}

計測系の剛性と原子間相互作用を考慮に入れた理論はす でに報告されている ${ }^{8}$. 本研究の考察に用いるため,もう一 度簡単にこの章で述べておく. Fig. 1(a)の様な弾性球と剛 体平面の接触を考光る場合, その系の全エネルギーは弾性 球に蓄えられる弾性ひずみエネルギーと表面から界面にな

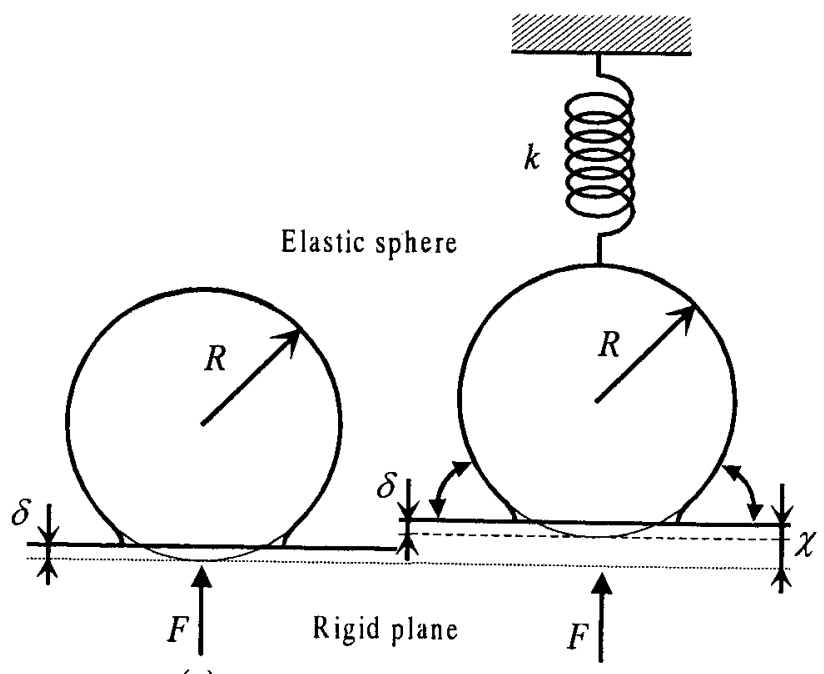

(a)

(b)

Fig. 1 Models of elastic contact for adhesion. (a) JKR model, (b) Measurement model.

*ここで言う，表面間相互作用は非接触分子間の長距離相互作用て ある。 
ることによるエネルギー変化の和で表されている，凝着力 を計測する場合には，計測系の剛性部に蓄えられる弾性ひ ずみエネルギーを考慮に入れなければならない.また，微 視的なレベルでは表面同士の原子間相互作用（接触前の原 子間相互作用あるいは接触後の接触部以外の原子間相互作 用）も影響する可能性がある。

計測系の剛性と表面間相互作用を考慮に入れた系を Fig. 1 (b)に示す。この系の全エネルギーは次のように表さ れる。

$$
E_{\text {total }}=E_{\text {elastic }}+E_{\text {interface }}+E_{\text {stiffness }}+E_{\text {surface }}
$$

ここで， $E_{\text {elastic }}$ は弾性球に蓄えられるひずみエネルギ 一, $E_{\text {interface }}$ は表面から界面に変わるときのエネルギー変 化で $-\pi a^{2} \Delta \gamma$ で表される. $a$ は接触円の半径, $\Delta \gamma$ は接触し ている球と平面を無限に引き離すのに必要な単位面積当た りのエネルギーで次式のように定義される。

$$
\Delta \gamma=\gamma_{\text {sphere }}+\gamma_{\text {plane }}-\gamma_{\text {sphere-plane }}
$$

$\gamma_{\text {sphere }}$ は球の表面エネルギー, $\gamma_{\text {plane }}$ は平面の表面エネルギ 一, $\gamma_{\text {sphere-plane }}$ は球と平面の界面エネルギーである。また, $E_{\text {stiffness }}$ は計測部の剛性に蓄えられるひずみエネルギーで $\frac{1}{2} k(x-\delta)^{2}$ である. $k$ は計測系の剛性率, $x$ は変位, $\delta$ は 弾性球の変形量である. E surface は表面間相互作用で(3)式て 表されるレナード-ジョーンズポテンシャルの重ね合わせ により導いている.

$$
V(r)=4 \varepsilon\left[(\sigma / r)^{12}-(\sigma / r)^{6}\right]
$$

ここで, $\varepsilon$ はエネルギーに関するパラメータ， $\sigma$ は距離に関 するパラメータ，rは原子間距離である。レナードージョー ンズポテンシャルは分子間ポテンシャルであり，重ね合わ せは球の非接触要素と半無限固体の全体積間で積分する. 球と半無限固体の原子密度と $\varepsilon$ は, 球と平面を無限大に引 き離すのに必要なエネルギー $\Delta \gamma$ の定義より $\Delta \gamma$ に含まれ る.

熱力学的平衡条件である(4)式を解くことによって変位と 力の関係を求めることができる.

$$
\left.\frac{\partial E_{\text {total }}}{\partial a}\right|_{x}=0
$$

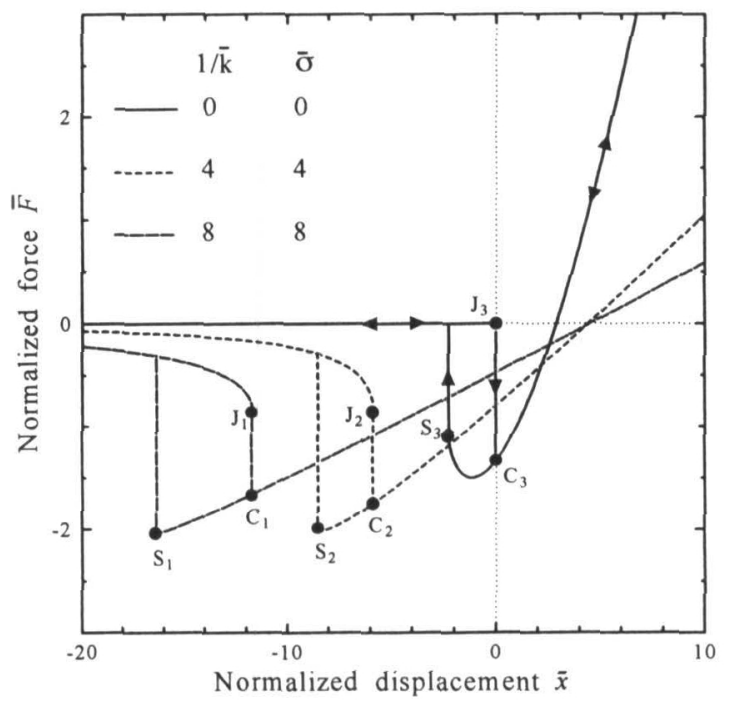

Fig. 2 Force curves calculated from theory in which the stiffness of the measurement system and surfacesurface interaction is taken into account.
(4)式より解析解を得ることは難しいが，すべての方程式と すべての物理量を無次元化することができている．そこで 無次元化した方程式を用い数值解析を行う。

Fig. 2 は数值解析によって得られた変位-力曲線である. 横軸は変位で正方向への変位が接近過程, 負方向への変位 が分離過程である. 球と平面が無限に離れているときの弾 性球の先端の位置を変位 $x=0$ とした，縦軸は力で正方向 が圧縮力, 負方向が引張力である. 変位と力の関係は計測 部のコンプライアンス $(1 / k)$ とレナード-ジョーンズポテ ンシャルの距離に関するパラメータ $(\sigma)$ の二つパラメー 夕により決定される。それぞれのパラメー夕は長さ $h$ を用 いて無次元化して用いている.

$$
\begin{aligned}
& h=\left[\pi^{2} R\left(1-\nu^{2}\right)^{2} \Delta \gamma^{2} / 2^{5} E^{2}\right]^{1 / 3} \\
& \bar{x}=x / h \\
& \bar{F}=F / \pi R \Delta \gamma \\
& 1 / \bar{k}=(1 / k) /(h / \pi R \Delta \gamma) \\
& \bar{\sigma}=\sigma / h
\end{aligned}
$$

ここで, $x$ は変位, $F$ は球と平面の間に働く全部の力, $R$ は 弾性球の半径, $E$ とレはそれぞれ弾性球のヤング率とポア ソン比である. Fig. 2 において球と平面を近づけていくと 原子間相互作用により引力が働き（ $\bar{\sigma}=0$ の時は働かな (), $J$ 点 $\left(J_{1}, J_{2}\right.$ および $J_{3}$ と記す) で点接触し凝着により 面接触となり $\mathrm{C}$ 点 $\left(\mathrm{C}_{1}, \mathrm{C}_{2}\right.$ および $\mathrm{C}_{3}$ と記す) に移行する. $\mathrm{C}$ 点より更に接近させると, 力は $\mathrm{C}$ 点上の曲線に沿って変 化する. 球と平面を離していくと $\mathrm{S}$ 点 $\left(\mathrm{S}_{1}, \mathrm{~S}_{2}\right.$ および $\mathrm{S}_{3}$ と 記す）で分離する. 計測系の剛性率が小さくなると球と平

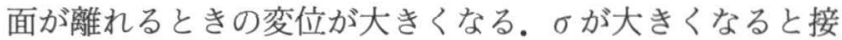
触前の引力が強くなっている. また, 分離するときの力も 強くなる。

\section{3． 実験装置及び実験方法}

変位-力曲線の計測は金とシリコンウェハーの間で行っ た. 金は純度 $99.95 \%$ ，線径 $100 \mu \mathrm{m}$ の金ワイヤーの先端を 大気中でガス炎中で溶融させ，凝固させることによって球 状にした. その形状を Fig. 3 の SEM 写真に示す.球の半径

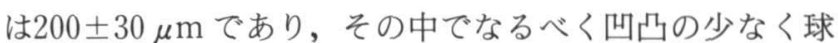
状であるものを選択して用いた。計測装置の詳細について は前報に述べている2).

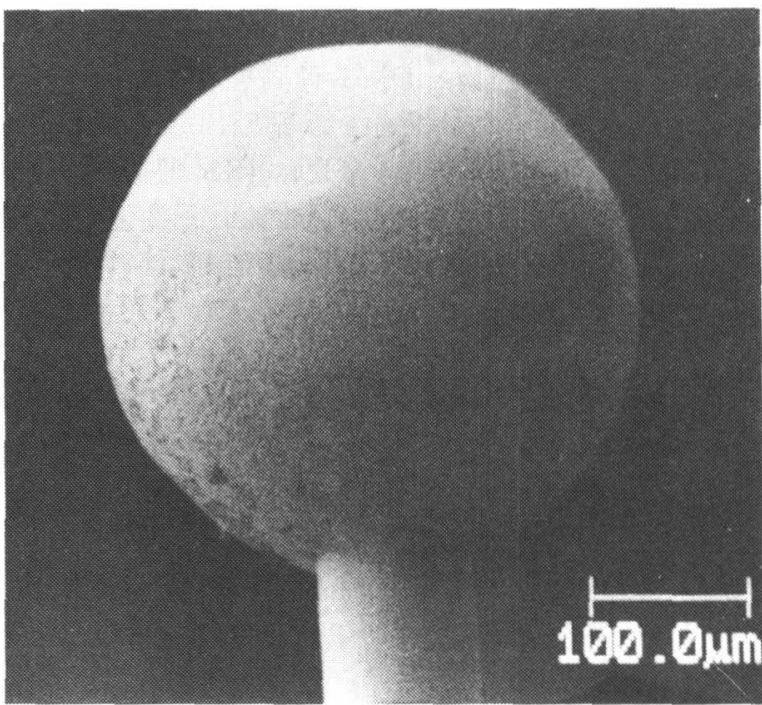

Fig. 3 SEM image of gold wire spherically terminated. 
試料をセットし超高真空チャンバー内でアルゴンイオン スパッタリングを行い，表面が清浄化していることを表面 分析によって確かめた。試料同士はモーターにより 0.5 $\mu \mathrm{m} / \mathrm{s}$ の一定速度で接近・分離させることができる. 金のボ ールとシリコンウェハーを接触させ数秒間保持した後試料 同士が分離するまで引き離した，加圧による抵抗の変化を 電圧に変換して, 増幅率 4 万倍程度のアンプにより増幅し て A/D コンバーターを通してコンピューターで記録し た. 計測中の真空度は $10^{-8} \mathrm{~Pa}$ 台の超高真空中である.

\section{4. 実験結果及び考察}

Fig. 4 に計測結果の一例を示す.横軸に時間 $t$ をとり,接 触開始を $t=0$ とした. 縦軸は力で加圧を正としている. 試 料同士を一定速度で近づけていくと，あるところで試料同 士は接触し引張力が生じる.一定荷重で保持した後一定速 度で引き離す過程において，荷重が零の状態では分離せず にある程度引張荷重をかけたところで試料は分離してい る.

Table 1 に計測システムの特性および試料の物性值を示 す. $R$ は金の球の半径で Fig. 3 の SEM 写真から $200 \mu \mathrm{m}$ とした. $E と \nu は$ 金球のヤング率とポアソン比でそれぞれ $78 \mathrm{GPa}$ と0.44とした。 $\Delta \gamma$ は金とシリコンの界面エネルギ 一がわからないので，オーダーを評価するため $2.0 \mathrm{~J} / \mathrm{m}^{2}$ と した ${ }^{9}$. 計測系の剛性率は $k=42 \mathrm{~N} / \mathrm{m}$ であるので $1 / \bar{k}=$ 10000 程度になる. Fig. 5 は Table 1 のパラメータを用い て本研究の計測システムで計測される変位一力曲線を理論 的に求めま結果である。四正確な值はわからないが原子 間距離程度のオーダーなので $\bar{\sigma}=0.05$ とした. Fig. 2 に示 した変位-力曲線より $1 / \bar{k}$ がかなり大きく $\bar{\sigma}$ が小さいた 女接触前の原子間相互作用はなく, 接触直後に引き合う力 はほとんど零である，また，分離するときの力は，ほぼ - $1.5 \pi R \Delta \gamma$ である.

Fig. 6 は変位と力の関係に Fig. 4 を変換した図である.

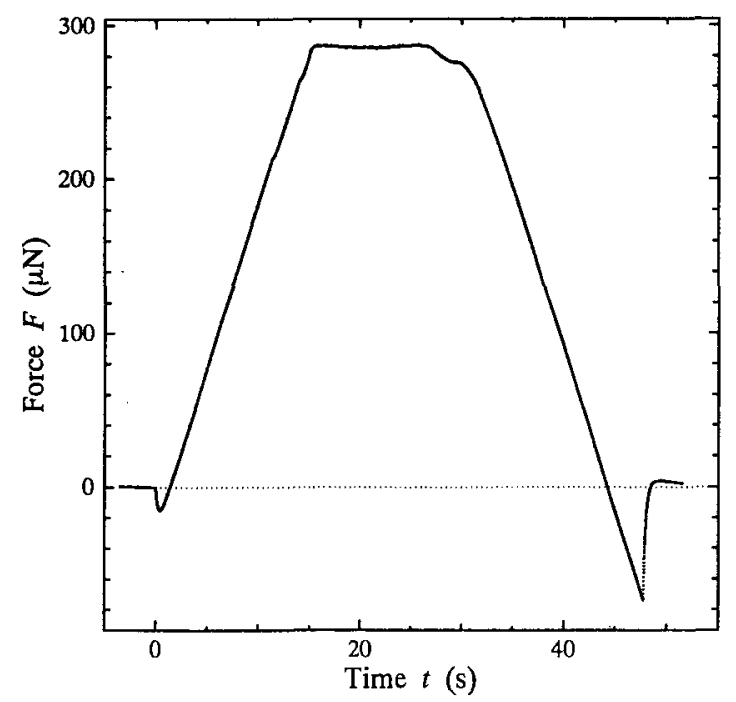

Fig. 4 An example of experimental results.

Table 1 The characteristic of the measurement system and material properties of specimens.

\begin{tabular}{cccccc}
\hline$R(\mu \mathrm{m})$ & $E(\mathrm{GPa})$ & $\nu$ & $\Delta \gamma\left(\mathrm{J} / \mathrm{m}^{2}\right)$ & $k(\mathrm{~N} / \mathrm{m})$ & $1 / k$ \\
\hline 200 & 78 & 0.44 & 2.0 & 42.0 & 10000 \\
\hline
\end{tabular}

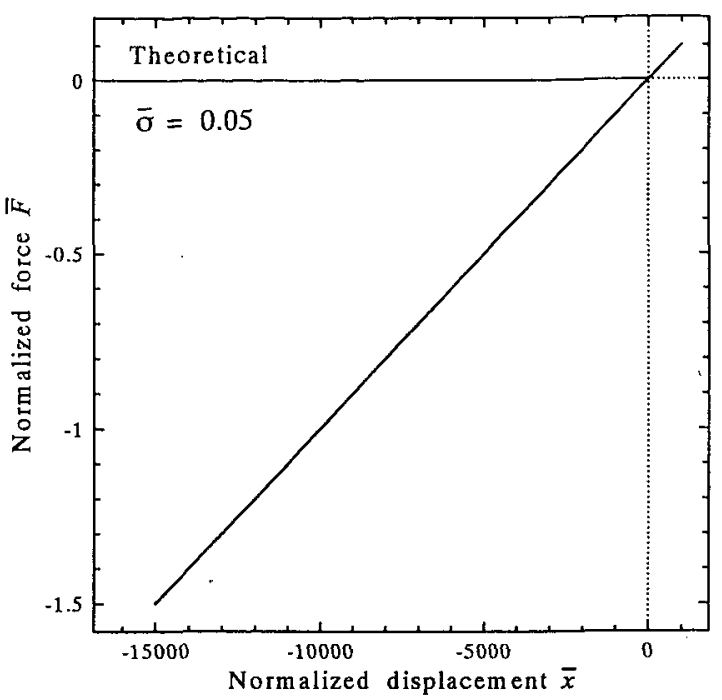

Fig. 5 Theoretical force curve to measure from the measurement system.

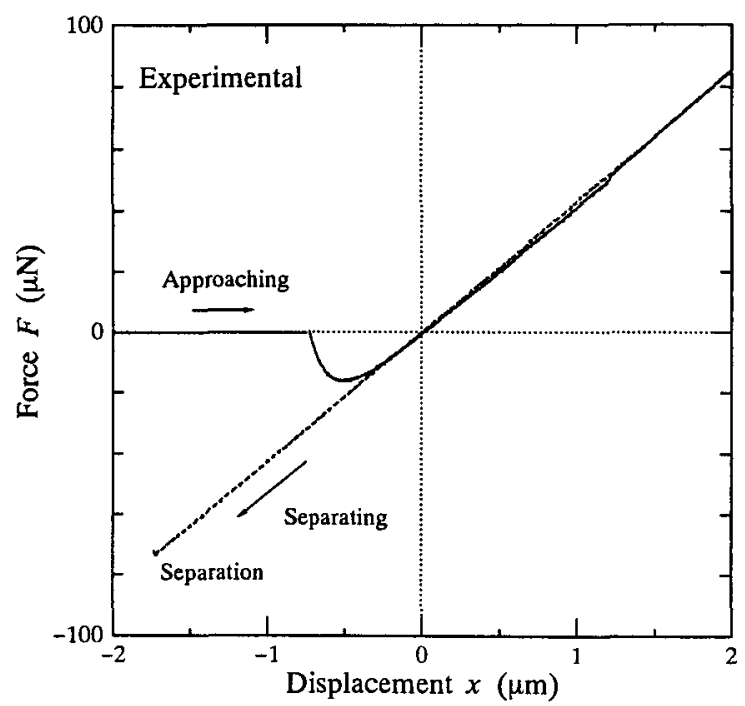

Fig. 6 An example of force curve obtained from experiment.

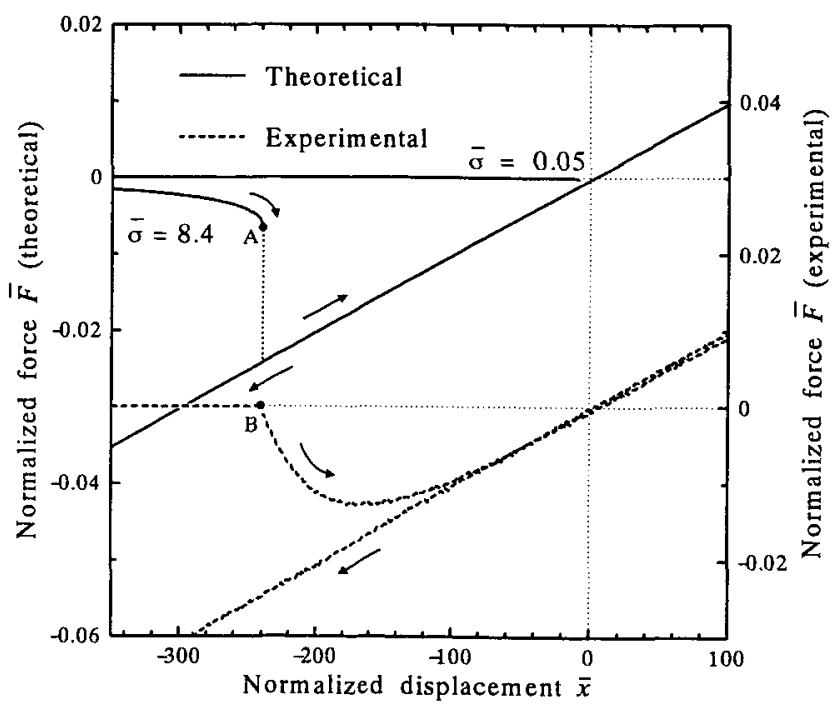

Fig. 7 Comparison between theoretical and experimental force curve. 
試料台を一定速度で動かしているので, 時間変化を距離変 化に変換することができる．Fig. 6 の分離過程において力 が零になる時の変位は Fig. 5 上り零であるので, $F=0$ の 時を $x=0$ とした。実線が接近過程であり, 破線が分離過程 を示している. $x=-0.75 \mu \mathrm{m}$ で接触し， $x=-1.7 \mu \mathrm{m}$ のと き, $F=-73 \mu \mathrm{N}$ で分離している.

Fig. 7 は実験結果と理論による変位一力曲線を比較した 図である。特に，接触直後の状態が理論と実験で異なるた めその部分を比較した。横軸は無次元化した変位，縦軸は 無次元化した力である. 左側の縦軸が理論，右側の縦軸が 実験に対する軸である。同じ軸に描写すると重なるので縦 軸をずらしてある。実線が理論值，破線が実験值を表して いる.Fig. 7 の実験值において,試料を接近させる際に生じ る最初の引力は変位一力曲線の形状により,接触と同時に生 じたものと考皇られる, 最初に接触が生じる変位 (Fig. 7 の A 点) が実線の変位值 (Fig. 7 のB点) と一致するように $\bar{\sigma}$ の値を推定すると $\bar{\sigma}=8.4$ となる. $\bar{\sigma}=8.4$ は, この場合 $\sigma=$ $25 \mathrm{~nm}$ に相当し原子間距離と比較しても約二桁大きい.ま た， $\bar{\sigma}=8.4$ とした計算結果では接触前の引力が働くことが 予測されているにも関わらず，実験結果では浮とんど働い ていない。このことからも $\bar{\sigma}=8.4$ は計測結果に当てはま らないと考えられる.

$\sigma$ は本来 $0.1 \sim 0.4 \mathrm{~nm}$ のオーダーで, 本研究の場合も $\bar{\sigma}$ $=0.05$ であろう. $\bar{\sigma}=0.05$ の場合は Fig. 7 に示したように 接触前の引力は無視できるほど小さいものである。また， $\bar{x}=-7.6$ で接触しそのとき働く力は $\bar{F}=-0.001$ である. しかし, 計測では $\bar{x}=-240$ で接触が開始している.これは 計測装置の振動が原因であると考えられる，接触開始時の 変位は実際の值では約ー750 nm である。計測システムは表 面分析装置内に構築されて扔り，真空ポンプの振動や試料 台を駆動するときの振動が考えられる。この実験の棓測で は離れた表面間に働く相互作用は無視できると考えられ る. 先述のとおり, Burnham らの AFM による実験では表 面間力を無視できないことが示唆されている，本研究の計 測に用いた金の球の半径は約 $200 \mu \mathrm{m}$ であり，このオーダ 一の大きさの半径では表面間相互作用は無視できることに なる、しかしながら, 球の半径が小さくなると $\bar{\sigma} は(9)$ 式に より大きくなるため，表面間の相互作用は無視できなくな ってくる．表面間の相互作用による最初に引き合う力は球 の半径が数十 nm で分離するときの力の約 $20 \%$ あるる.

実験と理論では引き離していくときの過程では傾きは一 致しているが, 球と平面が引き離れるときの力は実験値は 理論值（約 $-1.5 \pi R \Delta \gamma$ ) の十分の一程度の強さであった。
これは接触部の表面粗さによる真実接触面積の低下のため と考えられる，実験で最初に接触するとき，なだらかに接 触しているのは，試料が一定速度で移動しているため静的 なつりあいを完全に満たしていないことによると考えられ る。

\section{5. 結言}

超高真空の表面分析装置であるオージェ電子分光分析装 置内で金とシリコンを用いて変位と力の関係を計測した. 理論值と実験值の此較から本研究の計測システムでは表面 間の相互作用は無視できると考えられる。

実験結果は，計測系の剛性率を考慮に入れた弾性接触論 で大まかに説明でき，結果の細部を理解するためには表面 粗さや固体間相互作用についてさらなる検討が必要である ことがわかった、すなわち，本研究の計測システムにより 表面粗さや固体間相互作用の情報を得る可能性が示唆され た.

\section{参 考 文 献}

1) K. Takahashi, T. Iiyama, N. Katoh and T. Onzawa: Instru ment for measurement of adhesion forces in UHV surface analysis apparatus, J. Vac. Sci. Technol. A, 295 (1994), 889

2）水野亮二, 高橋邦夫, 恩澤忠男：金およびシリコンの間に働く固 体間凝着力の計測, 溶接学会論文集, Vol. 14, No. 3(1996), 523 ,

3) K.L. Johnson, K. Kendall and A.D. Roberts: Surface energy and the contact of elastic solids, Proc. R. Lond. A. 324 (1971), 301.

4) B.V.Derjaguin, V.M. Muller and Yu.P. Toporov: Effect of Contact Deformation on the Adhesion of Particles, J. Colloid Interface Sci., Vol. 53, No. 2 (1975), 314

5) V.M. Muller, V.M. Yushchenko and B.V. Derjaguin: On the Influence of Molecular Forces on the Deformation of an Elastic Sphere and Its Sticking to a Rigid Plane, J. Colloid Interface Sci., 77 (1980), 91.

6) K. Takahashi, R. Mizuno and T. Onzawa: Influence of the stiffness of measurement system on the elastic adhesional contact, J. Adhesion Sci. Technol., Vol. 9, No.11 (1995), 1451.

7) N A Burnham, R J Colton and H Pollock: Interpretation of force curves in force microscopy, Nanotechnology, 4 (1993), 64.

8) K. Takahashi and T. Onzawa: Effect of the stiffness of the measurement system on adhesion force curves in the elastic continuum limit, J. Adhesion Sci. Technol., Vol. 10, No.1 (1996), 17

9) Kunio Takahashi and Tadao Onzawa: Simple formula for the surface energy by a shifted-step-potential approximation, Physical Review B, Vol. 48, No. 8 (1993), 5689. 